\title{
Single-Step CMOS Compatible Fabrication of High Aspect Ratio Microchannels Embedded in Silicon ${ }^{\dagger}$
}

\author{
Marta Kluba 1,*, Aslihan Arslan ${ }^{2}$, Ronald Stoute ${ }^{3}$, James Muganda ${ }^{4}$ and Ronald Dekker ${ }^{1}$ \\ 1 Department of Microfabrication, Group: ECTM, TU Delft, Delft, The Netherlands; r.dekker@tudelft.nl \\ 2 Philips Healthcare, Best, The Netherlands; aslihanarslan@gmail.com \\ 3 Holst Centre, Eindhoven, The Netherlands; ronald.stoute@gmail.com \\ 4 Department of Mechanical Engineering, TU Eindhoven, Eindhoven, The Netherlands; \\ jamesmuganda@yahoo.com \\ * Correspondence: m.m.kluba@tudelft.nl; Tel.: +31-063-413-2458 \\ † Presented at the Eurosensors 2017 Conference, Paris, France, 3-6 September 2017.
}

Published: 11 August 2017

\begin{abstract}
This paper presents a new method for the CMOS compatible fabrication of microchannels integrated into a silicon substrate. In a single-step DRIE process (Deep Reactive Ion Etching) a network of microchannels with High Aspect Ratio (HAR) up to 10, can be etched in a silicon substrate through a mesh mask. In the same single etching step, multidimensional microchannels with various dimensions (width, length, and depth) can be obtained by tuning the process and design parameters. These fully embedded structures enable further wafer processing and integration of electronic components like sensors and actuators in wafers with microchannels.
\end{abstract}

Keywords: embedded microchannel; HAR; mesh mask; single-step DRIE (Bosch process)

\section{Introduction}

The field of microfluidics is rapidly expanding, and as a result the need for advanced microchannel fabrication technologies. The majority of the silicon based microfluidic devices, especially those with wide and/or deep microchannels like for instance integrated circuits for cooling or gas chromatography, are still sealed with wafer bonding techniques [1,2]. This cumbersome method limits miniaturization and further system integration possibilities.

Previous studies have already shown that it is possible to fabricate CMOS compatible microchannels that allow for the addition of actuators/sensors [3,4]. Furthermore, a recently proposed method for a two-step fabrication of sealable microchannels through a mesh mask, facilitates the development of the silicon based platforms like for instance Lab-on-a-Chip (LOC) or Organ-on-a-Chip (OOC). These high resolution silicon based microfluidic devices enable miniaturization and allow for further wafer processing and thus integration of actuators or sensors for in-situ stimulation or measurement. However, the major drawback of this method is the limited depth of the microfluidic channels, with maximum aspect ratio of 4 , due to the saturation in the DRIE (Deep Reactive Ion Ethcing) of narrow trenches at a depth of about $40 \mu \mathrm{m}$ [5].

This paper introduces a new CMOS compatible method for the fabrication of fully embedded multidimensional microchannels with high aspect ratio (HAR) in a single DRIE step.

\section{Materials and Methods}

The fabrication starts with the depositions of a $2 \mu \mathrm{m}$ thick layer of low-stress PECVD $\mathrm{SiO}_{2}$ on a silicon substrate. At the location of test channels, rows of parallel arrays with 56 different 
combinations of sub-micron size rectangular slits are dry-etched in the silicon dioxide using standard photoresist mask. The slits dimentions (see Figure 1) are varried as follows:

- $\quad$ Slit lenght (L): $6.0 \mu \mathrm{m}$; fixed,

- Slit width (W): $0.8 \mu \mathrm{m}, 1.0 \mu \mathrm{m}, 1.2 \mu \mathrm{m}, 1.4 \mu \mathrm{m}, 1.6 \mu \mathrm{m}, 1.8 \mu \mathrm{m}, 2.0 \mu \mathrm{m}$; variable,

- Slit distance (D): $0.6 \mu \mathrm{m}, 0.8 \mu \mathrm{m}, 1.0 \mu \mathrm{m}, 1.2 \mu \mathrm{m}, 1.4 \mu \mathrm{m}, 1.6 \mu \mathrm{m}, 1.8 \mu \mathrm{m}, 2.0 \mu \mathrm{m}$; variable.

Subsequently, channels in the silicon are etched through the meshed $\mathrm{SiO}_{2}$ hard mask in a single DRIE using the Bosch process. In this process cycles of: dry silicon etch (using $\mathrm{SF}_{6}$ ), walls passivation (using $\mathrm{C}_{4} \mathrm{~F}_{8}$ ), and break-through the passivation layer on the bottom of the trench; are alternatively performed and repeated in number of loops. This results in deep trenches with straight walls in the silicon. Figure 1 shows the graphical representation of the fabrication stages.

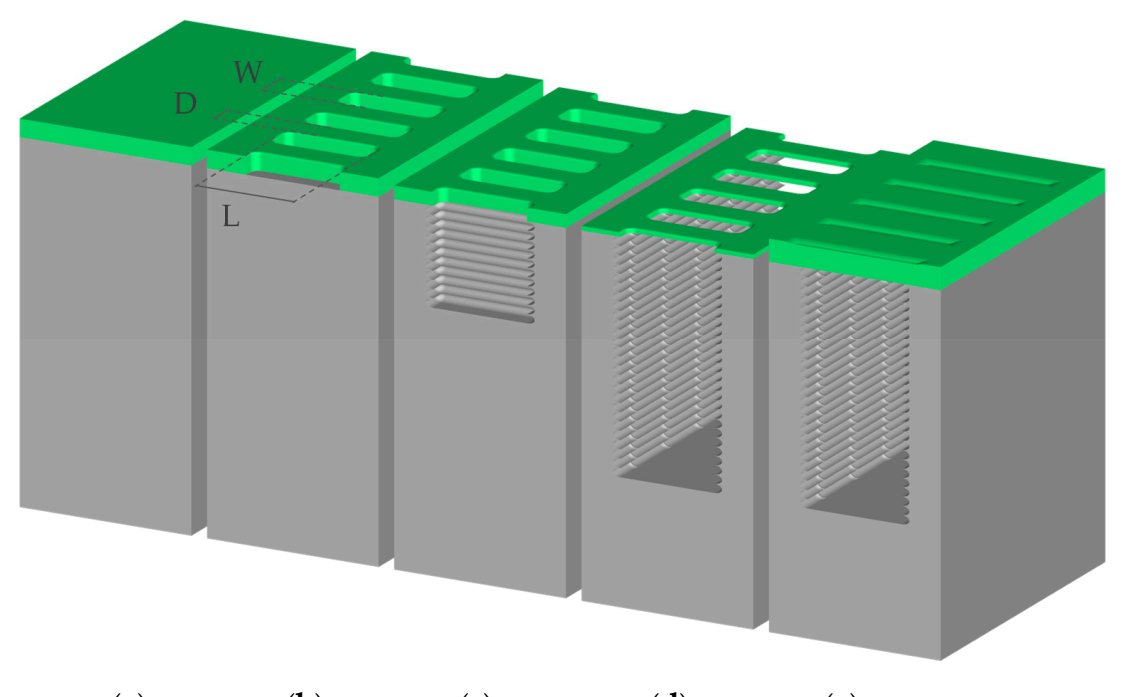

(a) (b)

(c)

(d)

(e)

Figure 1. HAR, embedded microchannels fabrication stages: (a) deposition of the silicon dioxide; (b) patterning the $\mathrm{SiO}_{2}$ hard etch mask; (c,d) simultaneous etch of trenches in the silicon and walls between them in the tuned single-step DRIE process; (e) closing the channels with a PECVD $\mathrm{SiO}_{2}$.

The duration of the silicon etch cycle varries from $1.5 \mathrm{~s}$ through $4 \mathrm{~s}$ up to $8 \mathrm{~s}$. The number of etchpassivation loops, and thus the total etch time, is increased from 10 loops up to 150 loops for long etch cycles $(8 \mathrm{~s})$ and up to 500 loops for short etch cycles $(1.5 \mathrm{~s})$. The total etch time is limited in such a way that at least $500 \mathrm{~nm}$ of the silicon dioxide hard mask is preserved on top of each channel. The preserved mesh mask is closed with a $2.5 \mu \mathrm{m}$ thick layer of $\mathrm{PECVD} \mathrm{SiO}_{2}$ to form the embedded network of microchannels.

The cross-section of each fabcricated channel is inspected in $45^{\circ}$ and $90^{\circ}$ tilt with SEM (Scanning Electron Microscope) to determin its depth and shape, and to examine the silicon dioxide mesh mask before and after closing the channel.

\section{Results and Discussion}

A number of microchannels were etched in silicon through the $2 \mu \mathrm{m}$ thick hard etch mask of silicon dioxide. At first it was observed that very uniform (approximately $590 \mu \mathrm{m}$ long and $6 \mu \mathrm{m}$ wide) channels with a depth of almost $60 \mu \mathrm{m}$ were etched in the silicon when the walls between single trenches were removed (Figure 2a). This results in aspect ratios of up to 10. The maximal reached depth of the trench was limited only by the thickness of the $\mathrm{SiO}_{2}$ mask, which had to be preserved in order to allow for CMOS-compatible and low-topography sealing of the structures with $\mathrm{PECVD} \mathrm{SiO}_{2}$ (Figure 2b,c).

The mechanism of etching trough the fine mesh mask and related to it walls removal was further studied in respect to process parameters: the etch cycle time and the number of etch-passivation loops; and design parameters: the slits width and the distance between the slits (slits length is fixed). 


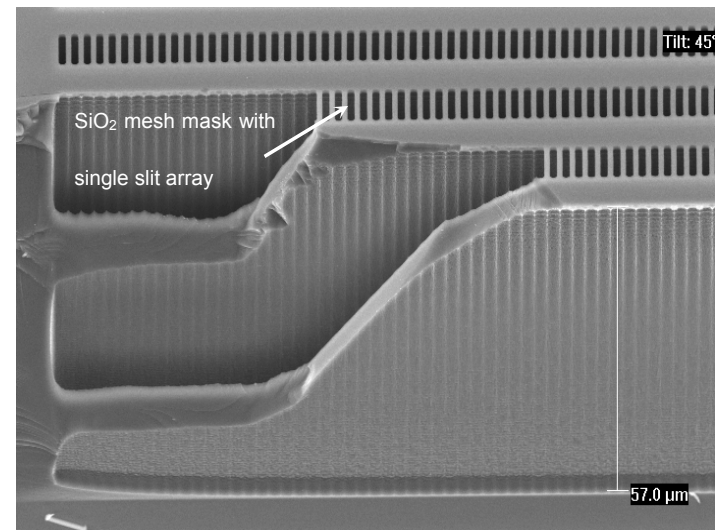

(a)

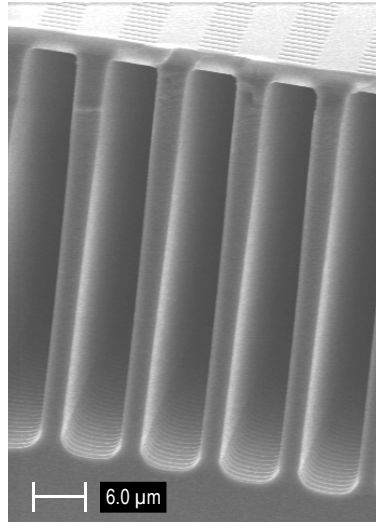

(b)

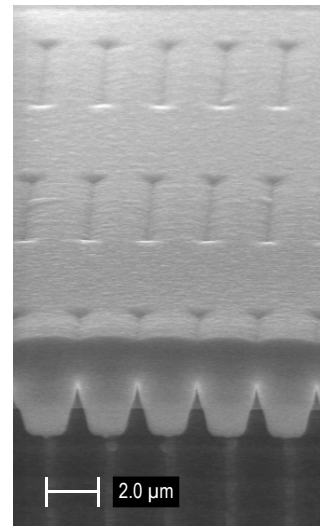

(c)

Figure 2. SEM image of $6 \mu \mathrm{m}$ wide and $57 \mu \mathrm{m}$ deep vertical microchannels etched through an oxide mesh mask in a single-step DRIE process: (a) cross-section through channels with preserved thin silicon dioxide mesh mask; (b) cross-section through a row of parallel channels after sealing them with PECVD SiO2; (c) cross-section through a sealing of an embedded channel.

\subsection{Process Parameters}

To test the influence of process parameters on the channels formation and their etch rate, three series of wafers with etch cycle times tecth $=\{1.5 \mathrm{~s} ; 4.0 \mathrm{~s} ; 8.0 \mathrm{~s}\}$, and increasing number of etchpassivation loops were etched through the oxide mesh with the same, fixed slits dimensions. The dependence on the trench depth from the total etch time, $t_{\text {total }}$ was calculated from:

$$
t_{\text {total }}=\text { number of loops } *\left(t_{\text {etch }}+t_{\text {overetch }}\right)
$$

where toveretch is the time of the silicon etch during the passivation break-through cycle after the passivation layer has been removed $\left(t_{\text {toveretch }}=1 \mathrm{~s}\right.$ ), was ploted in Figure 3a. For short total etch time $\left(t_{t o t a l} \leq 250 \mathrm{~s}\right)$ the etch rates and reached depths are comparable for all three series. For longer total etch time ( $\left.t_{\text {total }}>250 \mathrm{~s}\right)$, the walls between trenches with smaller scallops ( $t_{\text {etch }}=1.5 \mathrm{~s}$ ) are still present, and a slight trench depth saturation can be observed. For trenches with bigger scallops ( $t_{\text {etch }}=\{4 \mathrm{~s} ; 8 \mathrm{~s}\}$ ) the walls were removed at $t_{\text {total }} \approx 800 \mathrm{~s}$ and $t_{\text {total }} \approx 400 \mathrm{~s}$ respectively (the exact wall removal moment is hard to determine as it is a gradual process). The walls removal is directly connected with the shift in the etch rate curve allowing for achieving HAR structures without noticeable saturation signs within this experiment.

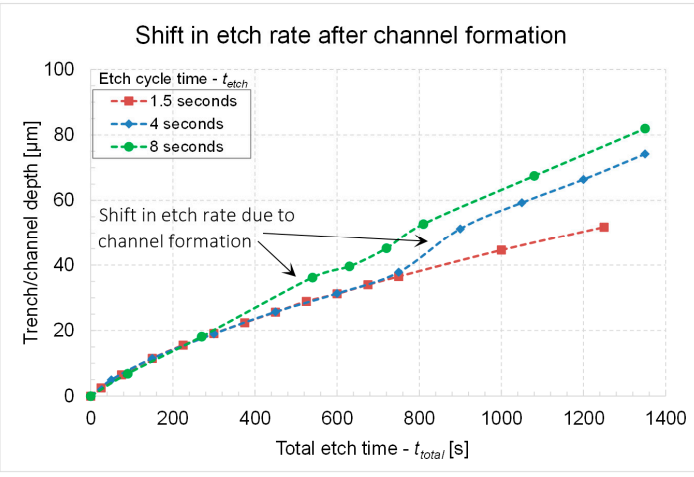

(a)

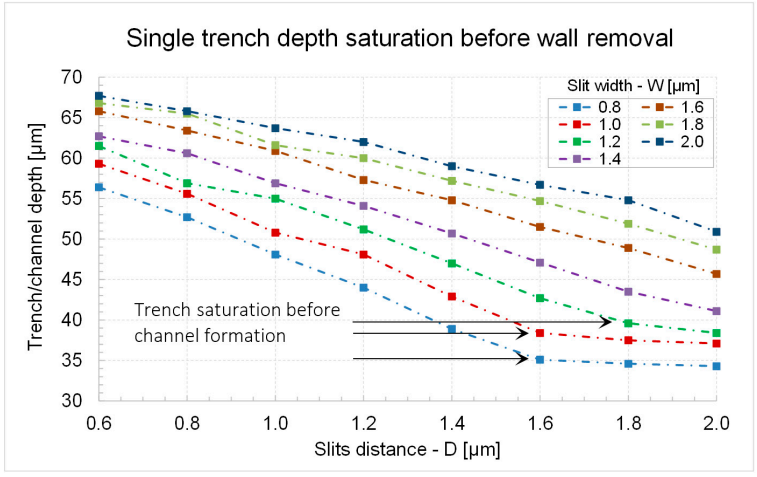

(b)

Figure 3. (a) The influence of the etch parameters on the channels formation and the etch rate of the structures (fixed design parameters); (b) The influence of the design parametrs on the channels formation and the structures depth (fixed process parameters). 


\subsection{Design Parameters}

In the second experiment the process parameters were fixed (90 loops, $t_{\text {etch }}=8 \mathrm{~s}$ ) while the mesh mask design parameters were varied: $\mathrm{W}[\mu \mathrm{m}]=\{0.8 ; 1.0 ; 1.2 ; 1.4 ; 1.6 ; 1.8 ; 2.0\}, \mathrm{D}[\mu \mathrm{m}]=\{0.6 ; 0.8 ; 1.0$; $1.2 ; 1.4 ; 1.6 ; 1.8 ; 2.0\}$; resulting in channels with various depths. The dependence of the trench depth on the slit parameters: width $W$ and the distance between the slits $D$ is plotted in Figure $3 b$. The trench depth is directly proportional to $\mathrm{W}$, corresponding to the open mask area, and inversely proportional to $\mathrm{D}$, corresponding to the trench wall thickness. The increase of the channels depth with decreasing slits distance is only noticable after the walls removal and thus formation of the channel. The thinner the walls between trenches is, the faster they merge into channels preventing its DRIE etch saturation.

\section{Conclusions}

With the new single-step DRIE process presented in this paper, it is possible to etch multidimetional microchannels with a uniform detpth and high aspect ratio of up to 10. By modifying the hard etch mesh mask design parameters (slit dimensions) and the Bosch process (DRIE) parameters, it is possible to simultaneously etch trenches and remove the walls between them forming a channel underneath the hard etch mesh mask. The channel formation underneath the mask changes the etching mechanism preventing DRIE etch saturation and therefore allows for the fabrication of HAR microchannels. After etching, the remaining mesh mask can be closed with $\mathrm{PECVD} \mathrm{SiO}_{2}$ to form the embedded microchannels. Channels with different dimensions can be etched in the same single-step process by tuning the mask design parameters.

Future work will include application studies, such as the integration of sensors on top of the embedded microchannels, and optimization of the mask in order to be able to reach even higher aspect ratios.

Acknowledgments: This research and resulting paper were carried on within InForMed project funded by ECSEL JU grant no: 2014-2-662155. The experiments and measurements were conducted in the Else Kooi Laboratory-CL100 cleanroom facility.

Conflicts of Interest: The authors declare no conflict of interest. The founding sponsors had no role in the design of the study; in the collection, analysis, or interpretation of data; in the writing of the manuscript, and in the decision to publish the results.

\section{References}

1. Zhang, X.; Han, X.; Sarvey, T.E.; Green, C.E.; Kottke, P.A.; Fedorov, A.G.; Joshi, Y.; Bakir, M.S. ThreeDimensional Integrated Circuit With Embedded Microfluidic Cooling: Technology, Thermal Performance, and Electrical Implications. J. Electron. Packag. 2016, 138, 1-9.

2. Lambertus, G.; Elstro, A.; Sensenig, K.; Potkay, J.; Agah, M.; Scheuering, S.; Wise, K.; Dorman, F.; Sacks, R. Design, fabrication, and evaluation of microfabricated columns for gas chromatography. Anal. Chem. 2004, 76, 2629-2637.

3. Huang, Y.; Mason, A.J. Lab-on-CMOS Integration of Microfluidics and Electrochemical Sensors. Lab. Chip 2013, 13, 3929-3934.

4. Dijkstra, M.; De Boer, M.J.; Berenschot, J.W.; Lammerink, T.S.J.; Wiegerink, R.J.; Elwenspoek, M. A versatile surface channel concept for microfluidic applications. J. Micromech. Microeng. 2007, 17, 1971.

5. Stoute, R.; Muganda, J.M.; Dahar, S.; Arslan, A.; Henderikx, R.J.M.; van Stiphout, P.C.M.; den Toonder, J.M.J.; Dekker, R. CMOS Compatible Embedded Microchannels. In Proceedings of the 20th International Conference on Miniaturized Systems for Chemistry and Life Sciences, Dublin, Ireland, 9-13 October 2016.

(C) 2017 by the authors. Licensee MDPI, Basel, Switzerland. This article is an open access article distributed under the terms and conditions of the Creative Commons Attribution (CC BY) license (http://creativecommons.org/licenses/by/4.0/). 